\title{
Frontières
}

\section{Bibliographie indicative sur la souffrance}

\section{Anne Létourneau}

Volume 17, numéro 2, printemps 2005

URI : https://id.erudit.org/iderudit/1073503ar

DOI : https://doi.org/10.7202/1073503ar

Aller au sommaire du numéro

Éditeur(s)

Université du Québec à Montréal

ISSN

1180-3479 (imprimé)

1916-0976 (numérique)

Découvrir la revue

Citer ce document

Létourneau, A. (2005). Bibliographie indicative sur la souffrance. Frontières, 17(2), 103-104. https://doi.org/10.7202/1073503ar d'utilisation que vous pouvez consulter en ligne.

https://apropos.erudit.org/fr/usagers/politique-dutilisation/ 


\section{BIBLIOGRAPHIE INDICATIVE SUR LA SOUFFRANCE}

Anne Létourneau, assistante à la rédaction

ANNEQUIN, Daniel (2002). T'as pas raison d'avoir mal: le combat d'un médecin contre la douleur de l'enfant, Paris, La Martinière.

ANNEQUIN, Daniel et Claire GUILLABERT (2002). La douleur chez l'enfant, Paris, Masson, coll. «Pédiatrie au quotidien ».

BOTBOL-BAUM, Mylène (1999). «Peut-on répondre à la souffrance, d'un point de vue médical?», Espace éthique, nos 7-8, p. 14-17.

BOULA, Jean-Gilles (2004). «De la douleur et de la souffrance à la qualité de vie du patient", Soins, $n^{\circ}$ 682, janvier/février, p. 30-31.

BROCA, Alain de (2002). Douleurs, soins palliatifs, deuils, Paris, Masson, collection "Modules transversaux», $n^{\circ} 6$.

BURLOUX, Gabriel (2004). Le corps et sa douleur, Paris, Dunod, coll. «Psychismes».

CASSIDY, Richard J., Anthony J. TAMBASCO et CATHOLIC BIBLICAL ASSOCIATION OF AMERICA (2001). The Bible on suffering: social and political implications, New York, Paulist Press.

DELBROUCK, Michel (dir.) (2003). Le burn-out du soignant. Le syndrome d'épuisement professionnel, Bruxelles, De Boeck, coll. "Oxalis».

DEL VOLGO, Marie-Josée (2003). La douleur du malade: clinique, psychanalyse et médecine, Ramonville Saint-Agne, Érès, coll. "Actualité de la psychanalyse».

ESTRYN-BÉHAR, Madeleine (1997). Stress et souffrance des soignants à I'hôpital: Reconnaissance, analyse et prévention, Paris, Éditions Estem.

FAINZANG, S. (2001). «Douleur, religion et médicaments», dans J.M. Marconot (dir.), Représentations des maladies et de la guérison dans la Bible et ses traditions, Montpellier, Université de Montpellier III/CNRS, p. 147-159.

FAINZANG, S. (2004). "Douleur et placebo. Approche anthropologique», Douleurs et analgésie, $\mathrm{n}^{\circ} 1, \mathrm{p} .33-37$.

FERGANE, Bernard et al. (2000). Douleur: soins préventifs et prise en charge, Paris, Flammarion/Médecine/Sciences, coll. «Pour réussir le DEl».

FERRAGUT, Éliane et al. (2002). Thérapies de la douleur, Paris, Masson, coll. "Psychosomatique, santé, douleur».

FERRAGUT, Éliane (2003), Le corps dans la prise en charge psychosomatique, suivi de: Enseignement capacité d'étude et de traitement de la douleur, Paris, Masson, coll. "Psychosomatique, santé, douleur».

FISCHER, Gustave-Nicolas (2003). Les blessures psychiques: la force de revivre, Paris, Odile Jacob.

FORTIN, Bruno (2000). Côtoyer la souffrance des personnes âgées, Montréal, Fides. FOUCART, Jean (2003). Sociologie de la souffrance, Bruxelles, De Boeck, coll. "Ouvertures sociologiques».

HEEMSKERK, Margaretha T. (2000). Suffering in the Mu'tazilite theology: Abd al-Jabbar's teaching on pain and divine justice, Leiden, E.J. Brill, coll. «Islamic philosophy, theology, and science», vol. 41.

JACQUEMIN, Dominique (2002). Bioéthique, médecine et souffrance: jalons pour une théologie de l'échec, Montréal, Médiaspaul, coll. «Interpellations», nº 13.

LEFEBVRE-CHAPIRO, Sylvie (2003). Douleur et sujet âgé, Paris, Phase 5, coll. «Douleur et».

LE BRETON, David (1995). Anthropologie de la douleur, Paris, Éditions Métailié.

LEVINAS, Emmanuel (1998). "La souffrance inutile», dans Entre nous. Essais sur le penser-à-l'autre, Paris, Grasset, p. 100-112.

LIVINGSTON, William Kenneth (1998). Pain and suffering, Seattle, IASP Press.

MARTIN, Nicolas et Antoine SPIRE (2004). Dieu aime-t-il les malades? Les religions monothéistes face à la maladie, Paris, A. Carrière.

METZGER, Christiane et al. (2004). Soins infirmiers et douleur, Paris, Masson, coll. "Savoir et pratique infirmière».

MEYNADIER, Jacques (2002). Douleur et cancer, Paris, Phase 5, coll. «Douleur et».

O'HARA, Doreen (2002). Heal the pain, comfort the spirit: the hows and whys of modern pain treatments, Philadelphia, University of Pennsylvania Press. 
PRATT, Jean-François (2003). Mots pour maux, Paris, L'Harmattan, coll. «Psychanalyse et civilisations».

PRÉVOST, Jean-Pierre (1997). Dire ou maudire sa souffrance? Les enjeux du livre de Job, $3^{\mathrm{e}}$ éd., Montréal, Éditions Paulines/Centre de pastorale en milieu ouvrier, coll. "Déclic», n 13.

QUENEAU, Patrice et al. (2000). Le médecin, le malade et la douleur, Paris, Masson.

RICOEUR, Paul (1994). "La souffrance n'est pas la douleur", dans Jean-Marie VON KAENEL et Béatrice AJCHENBAUM-BOFFETY (dir.), Souffrances, corps et âmes, épreuves partagées, Paris, Autrement, coll. «Série Mutations», n 142, p. 58-70.

VASSORT, Érik et Jocelyne LE GALL (2003). Douleur: programme d'amélioration de la qualité: mode d'emploi, Paris, Masson, coll. «Objectifs en management hospitalier ». 